Cite this: RSC Adv., 2013, 3, 24215

Received 26th July 2013

Accepted 9th October 2013

DOI: $10.1039 / \mathrm{c} 3 \mathrm{ra43930e}$

www.rsc.org/advances

\section{Noncovalent functionalization of a nanofibrous network with a bio-inspired heavy metal binding peptide $\dagger$}

\author{
Ruslan Garifullin, Oya Ustahuseyin, $\$$ Asli Celebioglu, Goksu Cinar, Tamer Uyar \\ and Mustafa O. Guler*
}

Peptide-polymer nanofibrous networks can be developed to obtain hybrid systems providing both functionalities of peptides and stability and processability of the polymers. In this work, a bio-inspired heavy metal binding peptide was synthesized and noncovalently immobilized on water-insoluble electrospun hydroxypropyl-beta-cyclodextrin nanofibers (CDNF). The peptide functionalized hybrid nanofibers were able to bind to heavy metal ions and facilitated removal of metal ions from water. The peptide-polymer scavenging system has potential for development of further molecular recognition systems with various peptide sequences or host-guest inclusion complexes.

\section{Introduction}

Nature is a constant inspiration source for researchers solving a wide range of critical problems of the modern age. Metal ions are essential in many processes in nature such as photosynthesis, ${ }^{1}$ water oxidation, ${ }^{1}$ respiration ${ }^{2}$ and nitrogen fixation. ${ }^{3}$ Although metal ions are an essential part of metalloproteins and beneficial at optimum concentration levels, heavy metal ions pose a serious threat for human health even at low concentrations..$^{4-6}$ These metal ions can contaminate and spread through natural water sources. Several plants, fungi, nematodas and algae have mechanisms to cope with heavy metal contaminations. ${ }^{7}$ Their defense mechanism utilizes phytochelatins, which are known for their heavy metal detoxification capability. ${ }^{8}$ The phytochelatins are short peptides consisting of $\gamma$-Glu-Cys repeats and capable of binding heavy metal ions via thiolate coordination. ${ }^{9,10}$ The $\alpha$-carboxylate group of glutamic acid and sulfhydryl group of cysteine in phytochelatins coordinate to positively charged metal ions and act as chelating agent. Similar to $\gamma$-Glu-Cys units of phytochelatin, it was previously reported that Glu-Cys repeating units in phytochelatin-related peptides showed binding abilities toward various heavy metals. ${ }^{11}$ Also, synthetic peptides inspired by phytochelatins were used for different applications such as determining the size of the nanocrystals

Institute of Materials Science and Nanotechnology, National Nanotechnology Research Center (UNAM), Bilkent University, Ankara, Turkey, 06800. E-mail: moguler@unam. bilkent.edu.tr; Fax: +90 (312) 266 4365; Tel: +90 (312) 2903552

$\dagger$ Electronic supplementary information (ESI) available. See DOI: 10.1039/c3ra43930e

$\ddagger$ These authors contributed equally to this manuscript. produced in biomimetic synthesis processes, ${ }^{12,13}$ and binding of heavy metals for biosensor applications. ${ }^{14}$

Functionalized fibrous polymeric materials and natural polymers have been used for different purposes such as increase of fiber mechanical stability ${ }^{15}$ or drug delivery. ${ }^{16}$ In addition, straightforward immobilization of peptides on the polymeric materials can provide vast potential for new materials design. Noncovalent interactions can offer a suitable tool in achieving easy functionalization of polymers. For example, cyclodextrins are toroid shaped cyclic oligosaccharides with a hydrophobic inner cavity and a hydrophilic exterior; and they can form stable noncovalent host-guest inclusion complexes. ${ }^{17,18} \mathrm{An}$ adamantyl moiety is known to be included and held strongly in cyclodextrin..$^{19-21}$ Nearly perfect match and strong binding between the cavity of $\beta$-cyclodextrin and guest diameter of adamantyl group was showed previously. ${ }^{22}$

In this study, a bioinspired metal binding peptide was noncovalently immobilized on the surface of polymer network through host-guest inclusion mechanism (Scheme 1). We synthesized a phytochelatin inspired peptide (PMP) including Glu-Cys repeating units conjugated to an adamantyl moiety. The PMP molecule was immobilized on a fibrous solid support consisting of water-insoluble, crosslinked, electrospun hydroxypropyl-beta-cyclodextrin nanofibers (CDNF). Noncovalent functionalization of CDNF nanofibers with PMP molecule was achieved by host-guest inclusion complex formation between the cyclodextrin and the adamantyl units. The PMP-CDNF hybrid fibrous solid network was used to scavenge highly toxic metal ions including $\mathrm{Cd}^{\mathrm{II}}, \mathrm{Ni}^{\mathrm{II}}$ and $\mathrm{Cr}^{\mathrm{VI}}$, from aqueous solutions. 


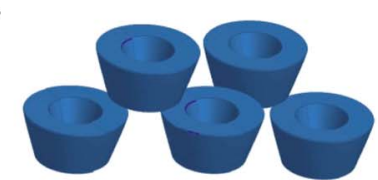

c.

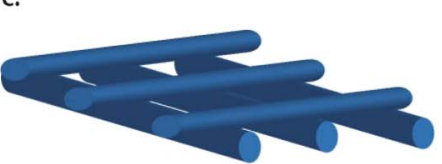

d.

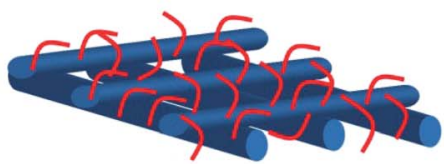

e.

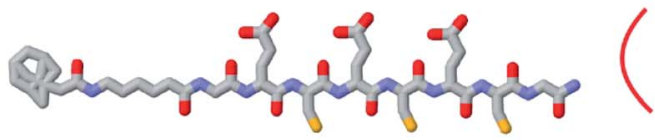

ADAc-6-Ahx-GECECECG-Am b.

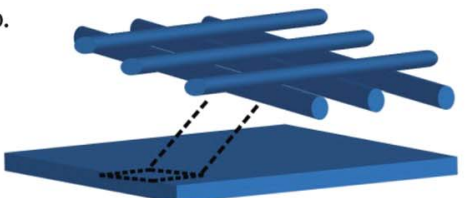

Peptide Functionalization

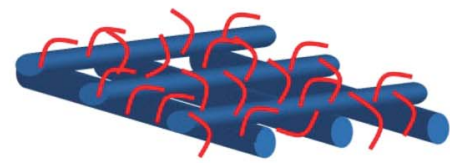

Metal lon Scavenging
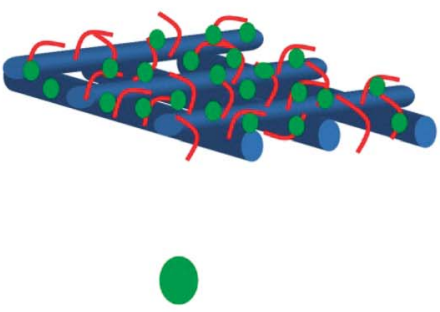

Metal ion

Scheme 1 (a) Schematic drawing of HPBCD molecules. (b) Electrospun CDNF as a water-insoluble support. (c) CDNF support was functionalized with a metal ion binding peptide via its adamantyl moiety. (d) Metal ions were removed from water through scavenging with PMP molecule. (e) Chemical structure and representative illustration of the peptide molecule and metal ions.

\section{Experimental section}

\section{Materials}

9-Fluorenylmethoxycarbonyl protected amino acids, MBHA rink amide resin, HBTU (O-benzotriazole- $N, N, N^{\prime}, N^{\prime}$-tetramethyl-uronium-hexafluoro-phosphate) are purchased from Novabiochem. Lauric acid is purchased from MERCK. All chemicals were used directly without any further purification.

\section{Peptide synthesis}

Peptide molecule was constructed on MBHA Rink Amide resin. Amino acid couplings were performed with 2 equivalents of Fmocprotected amino acid, 1.95 equivalents of HBTU and 2 equivalents of DIEA ( $N, N$-diisopropylethylamine) for $3 \mathrm{~h}$. Fmoc removals were performed with $20 \%$ piperidine/DMF solution for $20 \mathrm{~min}$. Cleavage of the peptides from the resin was carried out with a mixture of TFA : TIS : $\mathrm{H}_{2} \mathrm{O}:$ EDT in ratio of $92.5: 2.5: 2.5: 2.5$ for $2 \mathrm{~h}$. Excess TFA was removed by rotary evaporation. The remaining viscous peptide solution was triturated with cold ether and the resulting white product was dried under vacuum. The peptide molecule was purified with dialysis. For this purpose, Spectra/ Por ${ }^{\circledR}$ Biotech Cellulose Ester dialysis membrane with 100-500 Da molecular weight cut-off was used. The peptide solution was dialyzed for 4 days. After the dialysis, the peptide solution was freeze-dried.

\section{Liquid chromatography-mass spectrometry}

Agilent Technologies 6530 Accurate-Mass QTOF system equipped with a Zorbax SB-C8 column was used for liquid chromatography-mass spectrometry (LC-MS) analysis. A gradient of
$\mathrm{H}_{2} \mathrm{O}\left(0.1 \% \mathrm{NH}_{4} \mathrm{OH}\right)$ and acetonitrile $(\mathrm{AcN})\left(0.1 \% \mathrm{NH}_{4} \mathrm{OH}\right)$ was used as mobile phase. Purity of the PMP molecule was confirmed by LC-MS (Fig. S1b and c广).

\section{Electrospinning of poly-hydroxypropyl-beta-cyclodextrin nanofibers (CDNF)}

Preparation of CDNF was performed by addition of epichlorohydrin as crosslinking agent into the highly concentrated HP $\beta C D$ alkaline solution. Electrospinning of clear solution was carried at $15 \mathrm{kV}$ with $10 \mathrm{~cm}$ tip-to-collector distance and $1 \mathrm{~mL} \mathrm{~h}^{-1}$ flow rate. Finally, excess amount of unreacted CD and epicholorohydrin were removed by washing nanofibers with water and ethanol.

\section{Functionalization of CDNF with PMPs}

2.5 mM PMP solution was prepared with tris(2-carboxyethyl) phosphine hydrochloride (TCEP) containing $50 \mathrm{mM}$ TRIS buffer at pH 8.0. Then, CDNF network was immersed into the PMP solution and incubated for $24 \mathrm{~h}$. Then, the network was removed from the solution, washed and dried at ambient conditions.

\section{UV absorbance measurements}

$2 \mathrm{~mL}$ of $20 \mu \mathrm{M}$ metal ion solutions in $50 \mathrm{mM}$ Tris buffer at pH 8.0 was titrated with $5 \mu \mathrm{L}$ aliquots of $2.4 \mathrm{mM}$ peptide solution prepared from $12 \mathrm{mM}$ stock solution in $36 \mathrm{mM}$ tris(2-carboxyethyl) phosphine hydrochloride (TCEP-HCl) in Tris buffer at $\mathrm{pH}$ 8.0. After addition of peptide solution into metal solutions, the mixture was incubated for $45 \mathrm{~min}$ for equilibrium. Then, absorbance of the solution was measured 
between 200 and $400 \mathrm{~nm}$ with Cary 5000 UV-Vis-NIR spectrophotometer. Before the measurements, absorbance of buffer was corrected as blank.

\section{Isothermal titration calorimetry}

Isothermal titration calorimetry (ITC) analysis was performed by a Microcal ITC 200. Binding of metal ions to PMP-HP $\beta C D$ and HP $\beta C D$ were measured. For ITC analysis of PMP-HP $\beta C D$, PMP was dissolved in $36 \mathrm{mM}$ tris(2-carboxyethyl) phosphine hydrochloride (TCEP-HCl) in TRIS buffer $\mathrm{pH}$ 8.0. Then, the solution was mixed with HP $\beta C D$ in equal mol with PMP. For ITC analysis of HP $\beta C D, H P \beta C D$ was used in same amount as PMP-HP $\beta C D$ measurements. In ITC measurements, cell temperature was $25^{\circ} \mathrm{C}$, reference power was $5 \mu \mathrm{cal} \mathrm{s}^{-1}$, and stirring speed was $1200 \mathrm{rpm}$.

\section{Elemental analysis}

After PMP functionalization of the network, PMP content in PMP-CDNFs was analyzed with elemental analysis. Thermo Scientific FLASH 2000 series CHNS-O analyzer was used for the analysis. Only PMP, only CDNF nanofibers, PMP immobilized nanofibers and CDNF nanofibers treated with TRIS and TCEP samples were analyzed. As standard, 2,5(bis(5-tert-butyl-2-benzo-oxazol-2-yl)) thiophene powder was used. In addition, vanadium(v) oxide was used in each analysis as additive for compounds for complete thermal decomposition.

\section{Inductively coupled plasma-mass spectrometry}

Thermo X series II inductively coupled plasma-mass spectrometer (ICP-MS) was used to measure heavy metal ion concentrations. Functionalization of CDNF with PMPs was completed as given above. Initial heavy metal concentrations were $0.089,0.051$ and $0.096 \mathrm{mM}$ for $\mathrm{Cd}, \mathrm{Ni}$ and $\mathrm{Cr}$ metal solutions, respectively. At certain time intervals, the samples were taken from the solutions and 100 times diluted with $2 \%$ nitric acid solution for the analysis. The ICP-MS operating parameters were: dwell time $10000 \mathrm{~ms}$, channel per mass -1 , acquisition duration -7380 , channel spacing - 0.02, carrier gas-argon.

\section{X-ray photoelectron spectroscopy}

$\mathrm{X}$-ray photoelectron spectra of samples were recorded by using Thermo K-alpha monochromated high performance X-ray photoelectron spectrometer. The PMP-CDNF and CDNF were analyzed before and after incubation in metal ion solutions. The survey analyses were performed at 5 scans. High resolution spectra were recorded for the spectral regions depending on metal at pass energy of $50 \mathrm{eV}$ and 15 scans.

\section{FT-IR spectroscopy}

The Fourier Transform Infrared Spectrometer (FT-IR) (BrukerVERTEX 70) was used for the collection of infrared spectra of the samples. The CDNF and PMP-CDNF were mixed with potassium bromide $(\mathrm{KBr})$ and pressed as pellets. The scans (64 scans) were recorded between 4000 and $400 \mathrm{~cm}^{-1}$ at a resolution of $4 \mathrm{~cm}^{-1}$.

\section{Scanning electron microscopy}

Morphology of CDNF and PMP-CDNF was analyzed with FEI Quanta 200 FEG scanning electron microscope. All samples were coated with $3 \mathrm{~nm} \mathrm{Au-Pt}$ prior to imaging. For elemental mapping, CDNF was not coated and the analysis was performed at $5 \mathrm{kV}$.

\section{Raman spectroscopy}

WITec Alpha300S Scanning Near-field Optical Microscope with Raman module was used to characterize the samples. Nd:YAG $532 \mathrm{~nm}$ laser source was used in the experiments. Integration time was $0.53 \mathrm{~s}$. Number of accumulations was 50 for PMPCDNF sample and 10 for metal incubated samples. For Raman spectral image, $100 \mu \mathrm{m} \times 100 \mu \mathrm{m}$ was scanned with 50 points per line and 50 lines per image. Scan speed was $10.6 \mathrm{~s}$ per line and integration time was $0.21 \mathrm{~s}$.

\section{Results and discussions}

Peptide-polymer hybrid systems form a new class of soft materials combining advantages of chemical structure and functionality of biomolecules and benefits of synthetic polymers. ${ }^{23}$ In addition to exploiting peptides and proteins as novel structural components, a great deal of interest in harnessing their unique functions in a materials context exists. ${ }^{24}$ Peptide-polymer hybrid materials can find application in water remediation applications. ${ }^{25}$ However, aforementioned macromolecules usually possess poor handling and processing characteristics and are difficult to immobilize for the purposes of removal and recycling. Therefore, easy immobilization of a peptide on a polymer surface by noncovalent interactions would be useful for developing new functional polymers.

In this work, phytochelatin inspired peptide functionalization of a polymer network was achieved via host-guest interactions. Electrospinning is a widely used technique for development of functional sub-micron fibres using polymers for different applications. ${ }^{26}$ Water-insoluble CDNF network (Fig. 1a-c) was obtained by electrospinning technique. The CDNF network includes cyclodextrin (CD) moieties and an adamantyl group is known to form host-guest inclusion complex with $\beta$-CD. ${ }^{22}$ To immobilize PMP molecule on CDNF, an adamantyl unit was conjugated covalently to N-terminus of the peptide sequence by solid phase peptide synthesis method.

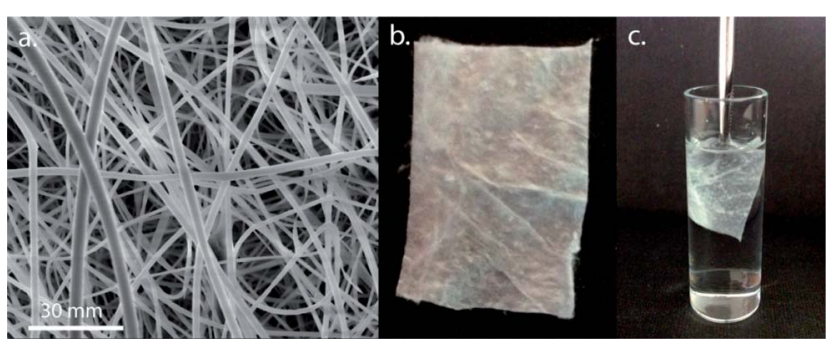

Fig. 1 (a) SEM image of electrospun CDNF. (b) A macroscale photographic image of CDNF. (c) Water-insoluble nature of CDNF. 


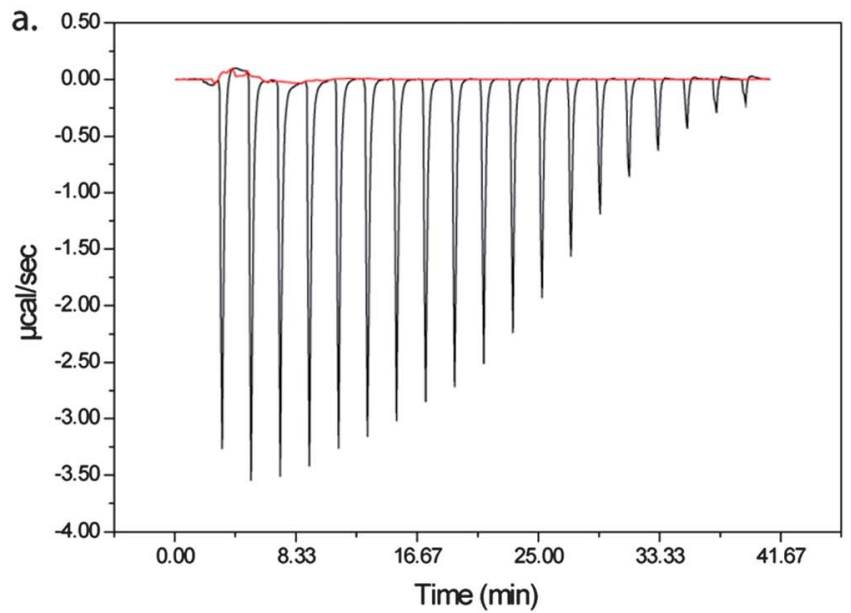

b.

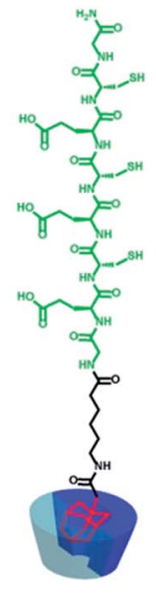

Fig. 2 (a) ITC curve obtained from titration of $\beta-C D$ with adamantane conjugated peptide molecule. (b) Schematic representation of interaction between $\beta$-CD and the peptide molecule. Adamantyl moiety of peptide molecule formed an inclusion complex with $\beta$-CD. The PMP molecule can bind to $\beta$-CD present in CDNF network.
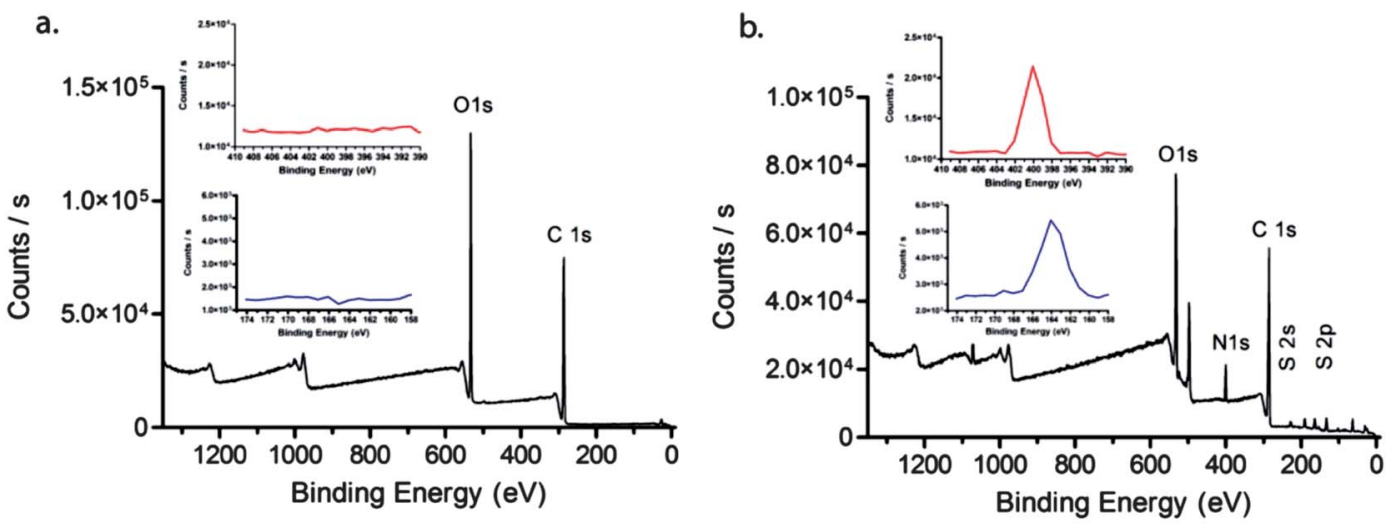

c.

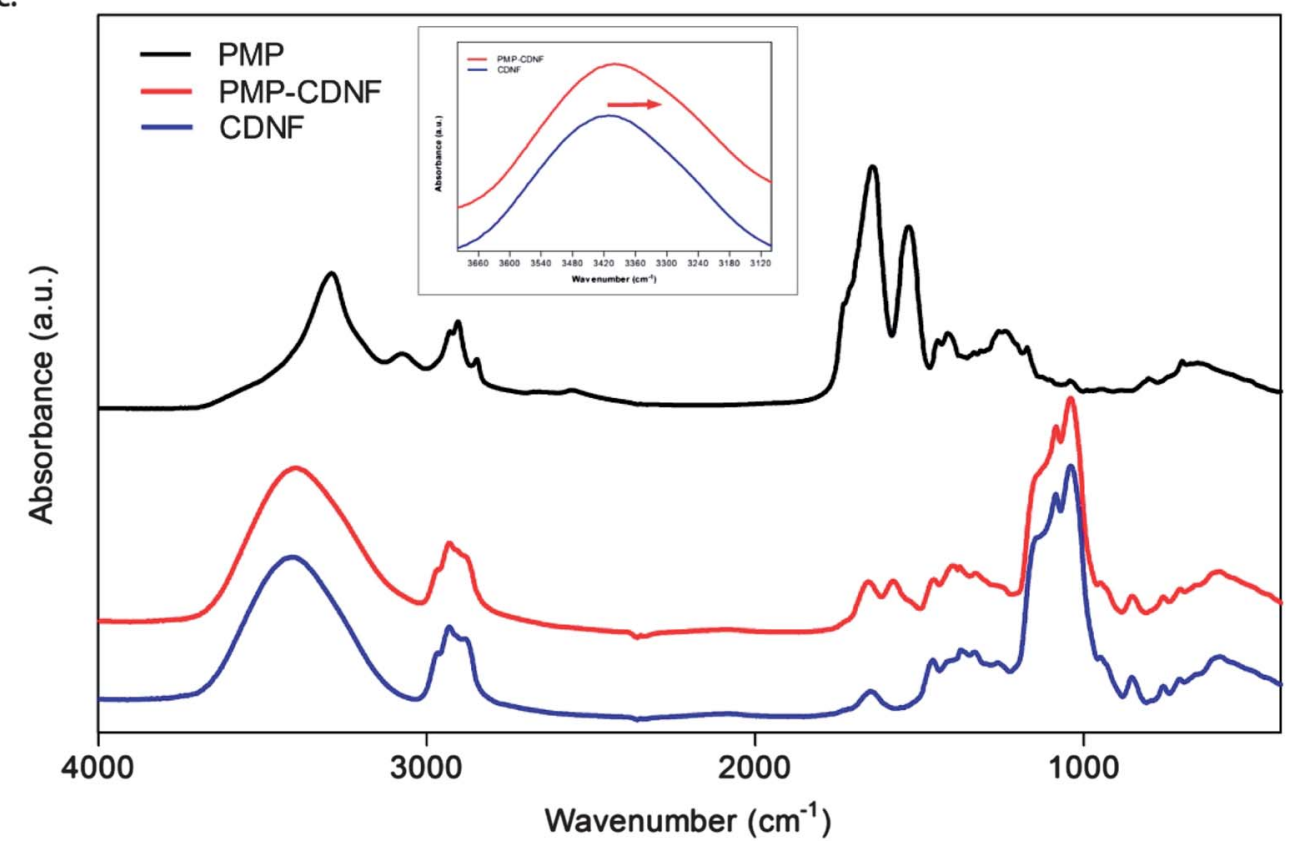

Fig. 3 XPS spectra of (a) CDNF and (b) PMP-CDNF. Insets show N1s (red line) and S2p (blue line) XPS spectra. After PMP-CDNF complex is formed, N1s and S2p peaks are present in XPS spectrum of PMP-CDNF (c) FTIR spectrum of PMP, CDNF and PMP functionalized CDNF. Inset indicates red shift in PMP-CDNF spectra compared to CDNF spectra from approximately $3440 \mathrm{~cm}^{-1}$ to $3408 \mathrm{~cm}^{-1}$. 
A 6-amino-hexanoic acid molecule was used as a spacer before conjugation of 1-adamantaneacetic acid to the peptide backbone. A glycine residue was added to both $\mathrm{C}$ and $\mathrm{N}$ termini of -(Glu-Cys) $)_{3}$ - peptide sequence (Scheme 1e and Fig. S1a $\uparrow$ ). Hostguest interaction between adamantyl moiety of PMP and $\beta$-CD was measured by ITC (Fig. 2). Titration of $\beta$-CD with PMP revealed a moderate binding affinity $\left(N=1.17, K_{\mathrm{d}}=3.85 \times\right.$ $10^{4} \mathrm{M}^{-1}$ ). Binding constant of the PMP and $\beta-\mathrm{CD}$ is similar to binding constant of adamantane acetate and $\beta-C D$ provided in the literature. ${ }^{22}$

The CDNF is a fibrous solid support consisting of waterinsoluble crosslinked HP $\beta C D$ nanofibers with submicron diameter. The CDNF can withstand water $(\mathrm{pH} \sim 5-8)$ without losing its integrity (Fig. 1c). Noncovalent functionalization of CDNF with PMP molecule was achieved by incubation of CDNF network in the PMP solution. The PMP-CDNF network was characterized by scanning electron microscopy and no significant morphology change was observed in CDNF after addition of the PMP molecules (Fig. 1a and S2a†). Physical appearance and insoluble character of CDNF were preserved after functionalization with the PMP molecules (Fig. S2a †).

The nature of interaction between PMP and CDNF was investigated by using X-ray photoelectron spectroscopy (XPS), FT-IR spectroscopy and Raman spectroscopy. Surface characterization of CDNF by XPS revealed only $\mathrm{C}$ and $\mathrm{O}$ atoms (Fig. 3a). On the other hand, PMP-CDNF network contained additional $\mathrm{N}$ and $\mathrm{S}$ element peaks indicating the presence of PMP (Fig. 3b). Amount of $\mathrm{N}$ and $\mathrm{S}$ elements were found to be $5.90 \%$ and $2.04 \%$, respectively on the surface of PMP-CDNF, (Table S1 $\dagger$ ). The FTIR spectra of CDNF and PMP-CDNF complex were obtained to investigate adamantane-cyclodextrin complex (Fig. 3c). Signal caused by multiple $-\mathrm{OH}$ groups on $\mathrm{HP} \beta \mathrm{CD}$ red-shifted from $3410 \mathrm{~cm}^{-1}$ to $3398 \mathrm{~cm}^{-1}$ due to interactions of hydroxyl groups with N-terminal carbonyl of the guest molecule. ${ }^{27,28}$ Moreover, amide II band of lyophilized $\mathrm{PMP}^{29}$ blue-shifted from $1533 \mathrm{~cm}^{-1}$ to $1581 \mathrm{~cm}^{-1}$ upon complexation with CDNF. Observed shift is indicative of increased in-plane $\mathrm{N}-\mathrm{H}$ bending, which is a result of significantly reduced peptide-peptide interactions. Complexation of PMP with CDNF disrupts interactions of individual PMP molecules (mainly H-bonds). Raman spectrum of CDNF (Fig. 4a) showed significant $\beta$-CD Raman bands ${ }^{30}$ such as symmetric stretching of $-\mathrm{C}-\mathrm{O}-\mathrm{C}$ at $938 \mathrm{~cm}^{-1}$, stretching vibration of $-\mathrm{CH}_{2}$ at $2934 \mathrm{~cm}^{-1}$, scissoring vibration of $-\mathrm{CH}_{2}$ and $-\mathrm{CH}$ at $1344 \mathrm{~cm}^{-1}$, and scissoring vibration of $-\mathrm{OH}$ at $1409 \mathrm{~cm}^{-1}$. Raman spectrum of PMP-CDNF revealed additional bands at $2450 \mathrm{~cm}^{-1}$ and $1650 \mathrm{~cm}^{-1}$ corresponding to stretching vibration of S-H and amide I vibration, ${ }^{31}$ respectively. Confocal Raman image of CDNF at $2934 \mathrm{~cm}^{-1}$ demonstrated HPßCD presence in the network (Fig. 4b).

PMP content in CDNF was determined quantitatively by elemental analysis. PMP, CDNF, CDNF treated with buffer and tris(2-carboxyethyl) phosphine hydrochloride (TCEP-HCl), and PMP-CDNF samples were analyzed with CHNS-O analyzer after drying under ambient conditions (Table S2 $\dagger$ ). Mass difference in $\mathrm{C}, \mathrm{H}, \mathrm{N}$, and $\mathrm{S}$ of PMP between experimental and theoretical values was only $1 \%$ (Table $\mathrm{S} 3 \dagger$ ). Negligible amount of $\mathrm{N}$ was detected in CDNF treated with buffer, although there is no $\mathrm{N}$ in

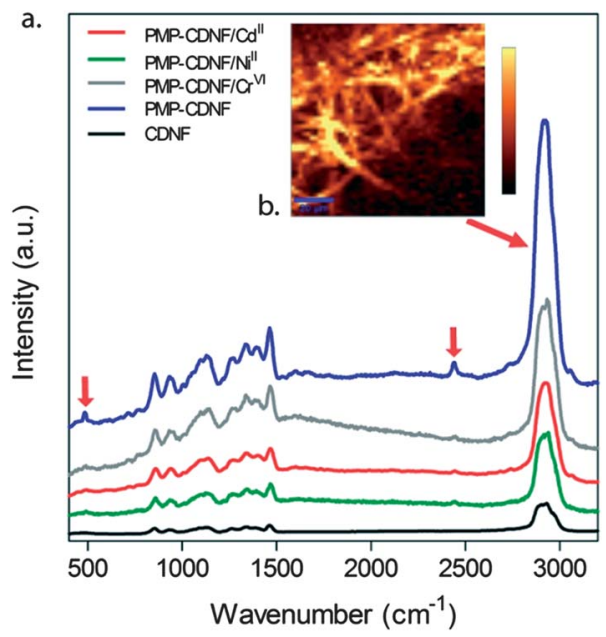

Fig. 4 (a) Raman spectra of CDNF, PMP-CDNF and PMP-CDNF after incubation with different metal solutions and mixture of the metal solutions. As amide I band at $1650 \mathrm{~cm}^{-1}$ and as -SH vibration at 510 and $2450 \mathrm{~cm}^{-1}$ was seen in PMP-CDNF. (b) Raman spectral image at $2934 \mathrm{~cm}^{-1}$ of $100 \mu \mathrm{m} \times 100 \mu \mathrm{m}$ scan area of CDNF.

the CDNF. The $\mathrm{N}$ content could be due to nonspecific adsorption of Tris buffer molecules.

Metal ions including $\mathrm{Cd}^{\mathrm{II}}, \mathrm{Ni}^{\mathrm{II}}$, and $\mathrm{Cr}^{\mathrm{VI}}$ were used to evaluate metal binding affinity of the PMP molecule. Interaction between metal ions and the PMP molecule was first studied by isothermal titration calorimetry (ITC). Solutions of $\mathrm{Cd}^{\mathrm{II}}, \mathrm{Ni}^{\mathrm{II}}$, and $\mathrm{Cr}^{\mathrm{VI}}$ were titrated with PMP solution at $\mathrm{pH} 8$ (Fig. 5a, S5a and S6a $\dagger$ ). ITC measurements showed greater affinity of PMP towards $\mathrm{Cd}^{\mathrm{II}}$ ions. The interaction between HP $\beta C D$ molecule and metal ions was negligible (Fig. S4a, S5b, and S6b $\dagger$ ). Interaction between metal ions, $\mathrm{Cd}^{\mathrm{II}}, \mathrm{Ni}^{\mathrm{II}}$, and $\mathrm{Cr}^{\mathrm{VI}}$, and the PMP molecule was also monitored through change in UV absorption of metal ion solutions. Increase in absorption peak at $c a$. $240 \mathrm{~nm}$ was observed for $\mathrm{Cd}^{\mathrm{II}}$ (Fig. 5b) and $\mathrm{Cr}^{\mathrm{VI}}$ metal ions (Fig. S6c $\dagger)^{32-35}$ due to ligand-to-metal charge transfer $\left(S \rightarrow \mathbf{M}^{n}\right)$ of Cd-S and Cr-S bonds; the increase leveled off after 1.5 molar eq. of PMP was titrated into the solution. Titration of $\mathrm{Cr}^{\mathrm{VI}}$ with the PMP molecule also revealed decrease in absorption bands at $c a .280$ and $375 \mathrm{~nm}$. Titration of $\mathrm{Ni}^{\mathrm{II}}$ revealed peak increase around $270 \mathrm{~nm}$ (Fig. S5c $\dagger$ ) due to $\mathrm{S} \rightarrow \mathrm{Ni}^{\mathrm{II}}$ charge transfer, ${ }^{36}$ which also leveled off at 1.5 molar eq. of PMP. Interaction between metal ions and PMP-CDNF system was verified by using PMP-functionalized and pristine CDNF, which were immersed into metal ion solutions $\left(\mathrm{Cd}^{\mathrm{II}}, \mathrm{Ni}^{\mathrm{II}}\right.$ and $\left.\mathrm{Cr}^{\mathrm{VI}}\right)$. Metal ions can be extracted from water by immersion of the PMPfunctionalized CDNF network into solution. Metal ion concentration in solution was monitored by inductively coupled plasma-mass spectrometer (ICP-MS) at different time intervals for $24 \mathrm{~h}$ incubation. Increase in metal binding also indirectly showed us the stability and functionality of PMP-CDNF scavenging system during incubation. The PMP-CDNF network captured $0.041 \pm 0.004 \mu \mathrm{mol} \mathrm{mg}{ }^{-1} \mathrm{Cd}^{\mathrm{II}}, 0.010 \pm 0.001 \mu \mathrm{mol}$ $\mathrm{mg}^{-1} \mathrm{Ni}^{\mathrm{II}}$ and $0.008 \pm 0.005 \mu \mathrm{mol} \mathrm{mg}{ }^{-1} \mathrm{Cr}^{\mathrm{VI}}$. However, pristine CDNF captured less than $0.005 \mu \mathrm{mol} \mathrm{mg}{ }^{-1} \mathrm{Cd}^{\mathrm{II}}, \mathrm{Ni}^{\mathrm{II}}$ and $\mathrm{Cr}^{\mathrm{VI}}$ (Fig. S7†). 


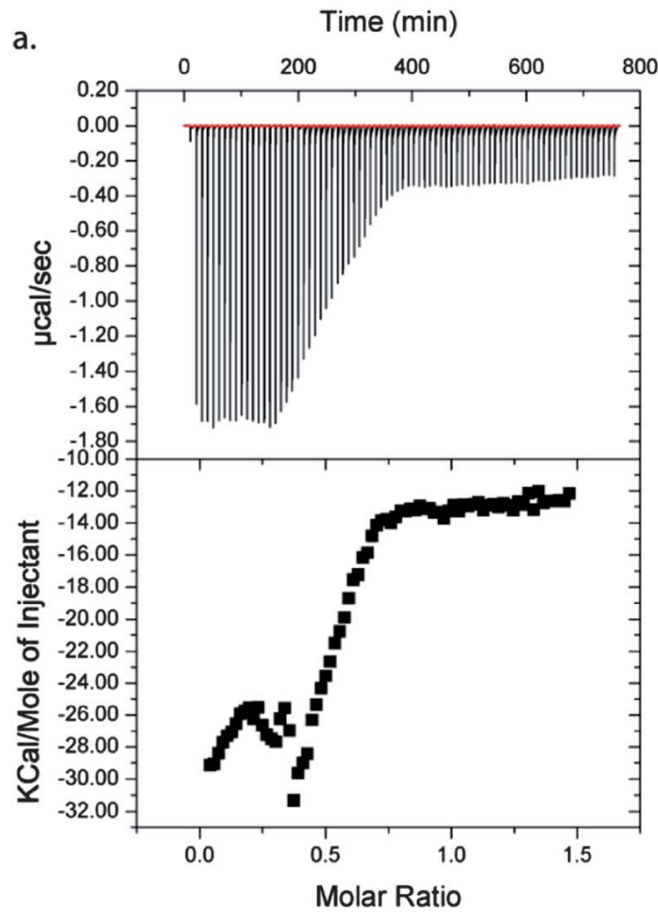

b.

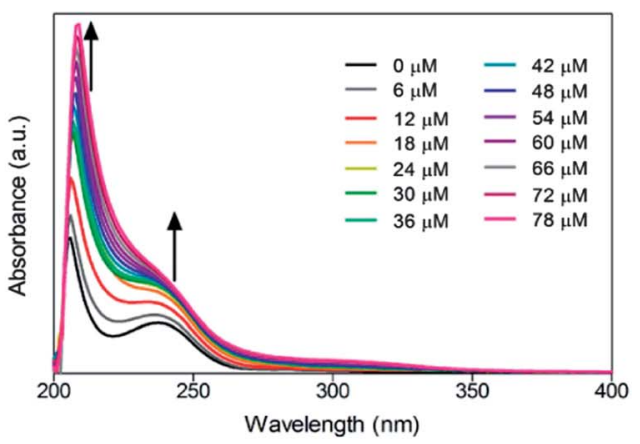

C.

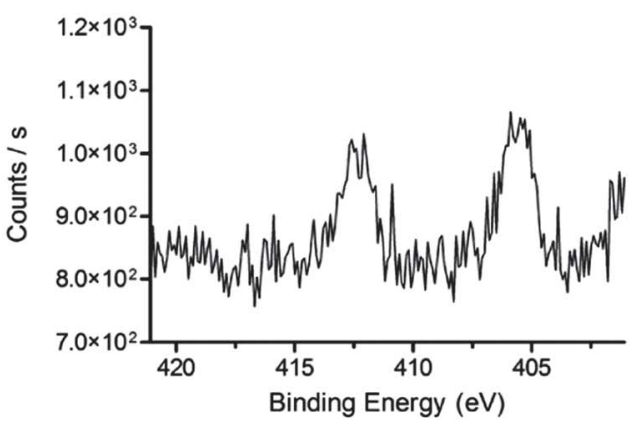

Fig. 5 (a) Isothermal titration curve of PMP with $\mathrm{CdCl}_{2}$ solution (b) $\mathrm{Cd} 3 \mathrm{~d}$ XPS spectrum of PMP-CDNF after incubation in Cd" solution. (c) Absorption change within $20 \mu \mathrm{M} \mathrm{CdCl} 2$ titration with PMP solution in $50 \mathrm{mM}$ Tris buffer at $\mathrm{pH} 8.0$.

In addition, no significant change was observed in morphology of the PMP-CDNF network upon binding to metal ions and the fibrous structure of the sample was preserved (Fig. S2b-d $\dagger$ ). After immersion of the sample into metal ion solution, a decrease in S-H vibration at PMP-CDNF sample was observed (Fig. 5a), which indicates interaction between sulfhydryl groups and metal ions. The XPS analysis of PMP-CDNF samples incubated in metal ion solutions demonstrated greater affinity of the system to $\mathrm{Cd}^{\mathrm{II}}$ (Fig. 5c). On the other hand, XPS spectra of $\mathrm{Cr}^{\mathrm{VI}}$ and $\mathrm{Ni}^{\mathrm{II}}$ did not show significant binding of these metal ions (Fig. S5d and S6d†).

\section{Conclusions}

In conclusion, we report design and synthesis of a heavy metal binding peptide sequence, which can be conjugated to an electrospun CDNF network through adamantane-cyclodextrin host-guest inclusion complex formation. Metal ion binding ability of the PMP molecule was verified with $\mathrm{Cd}^{\mathrm{II}}, \mathrm{Ni}^{\mathrm{II}}$, and $\mathrm{Cr}^{\mathrm{VI}}$ for PMP functionalized CDNF network in aqueous conditions. ITC measurements by titrations of metal ions with PMP molecule confirmed binding of the PMP molecules to corresponding metal ions. ITC measurement of PMP and $\beta$-CD showed that there is moderate binding affinity. Therefore, the PMP-CDNF system was utilized for metal ion scavenging. The amount of metal ions bound to PMP-CDNF fibrous network was quantified by ICP-MS, stability and functionality of the scavenging system was assessed during the metal incubation. Water-insoluble PMP-CDNF fibrous network preserved its fibrous structure without any deformation during metal ion scavenging process.
Hence, we successfully demonstrated design, synthesis, characterization, and application of a peptide-polymer hybrid scavenging system by using electrospun CDNF fibrous network as a solid support. On the other hand, metal binding capacity of such a scavenging system can be enhanced by using additional modifications on phytochelatin mimetic peptides and also polymer support. The peptide-polymer scavenging system has potential for development of further molecular recognition systems with various peptide sequences or host-guest inclusion complexes.

\section{Conflict of interest}

The authors declare no competing financial interests.

\section{Acknowledgements}

This work was partially supported by TÜBiTAK (109T603, 110M353, 112T602), TUBA-GEBIP, and FP7 Marie Curie IRG grants. A. C. and R. G. are supported by TUBITAK-BIDEB PhD fellowship. We thank Z. Erdogan for help in LC-MS and ITC, G. Celik for help in ICP-MS and Elemental Analysis, and Prof. A. Dana for assistance in Raman Spectroscopy.

\section{References}

1 G. W. Brudvig, W. F. Beck and J. C. Depaula, Annu. Rev. Biophys. Biophys. Chem., 1989, 18, 25-46.

2 O. Hammerich and J. Ulstrup, Bioinorganic Electrochemistry, Springer, 2008. 
3 P. J. Lea, Enzymes of Primary Metabolism, Academic Press, 1990.

4 M. Costa, Y. Yan, D. Zhao and K. Salnikow, J. Environ. Monit., 2003, 5, 222-223.

5 A. L. Hammond, Science, 1971, 171, 788-789.

6 N. Horzum, M. M. Demir, M. Nairat and T. Shahwan, RSC Adv., 2013, 3, 7828-7837.

7 C. Cobbett and P. Goldsbrough, Annu. Rev. Plant Biol., 2002, 53, 159-182.

8 J. Hall, J. Exp. Bot., 2002, 53, 1-11.

9 E. Grill, E.-L. Winnacker and M. H. Zenk, Proc. Natl. Acad. Sci. U. S. A., 1987, 84, 439-443.

10 W. E. Rauser, Annu. Rev. Biochem., 1990, 59, 61-86.

11 H. Satofuka, T. Fukui, M. Takagi, H. Atomi and T. Imanaka, J. Inorg. Biochem., 2001, 86, 595-602.

12 E. D. Spoerke and J. A. Voigt, Adv. Funct. Mater., 2007, 17, 2031-2037.

13 G. Spreitzer, J. M. Whitling, J. D. Madura and D. W. Wright, Chem. Commun., 2000, 209-210.

14 I. Bontidean, J. Ahlqvist, A. Mulchandani, W. Chen, W. Bae, R. K. Mehra, A. Mortari and E. Csöregi, Biosens. Bioelectron., 2003, 18, 547-553.

15 D. Dai and M. Fan, RSC Adv., 2013, 3, 4659-4665.

16 Q. Wang, N. Zhang, X. Hu, J. Yang and Y. Du, J. Biomed. Mater. Res., Part A, 2007, 82, 122-128.

17 A. Celebioglu and T. Uyar, Langmuir, 2011, 27, 6218-6226.

18 Y. Guo, S. Guo, J. Ren, Y. Zhai, S. Dong and E. Wang, ACS Nano, 2010, 4, 4001-4010.

19 O. Kretschmann, S. W. Choi, M. Miyauchi, I. Tomatsu, A. Harada and H. Ritter, Angew. Chem., Int. Ed., 2006, 45, 4361-4365.

20 T. Kakuta, Y. Takashima and A. Harada, Macromolecules, 2013, 46, 4575-4579.
21 M. Paolino, F. Ennen, S. Lamponi, M. Cernescu, B. Voit, A. Cappelli, D. Appelhans and H. Komber, Macromolecules, 2013, 46, 3215-3227.

22 M. R. Eftink, M. L. Andy, K. Bystrom, H. D. Perlmutter and D. S. Kristol, J. Am. Chem. Soc., 1989, 111, 6765-6772.

23 J. Y. Shu, B. Panganiban and T. Xu, Annu. Rev. Phys. Chem., 2013, 64, 631-657.

24 R. de la Rica and H. Matsui, Chem. Soc. Rev., 2010, 39, 34993509.

25 L. S. Witus and M. B. Francis, Acc. Chem. Res., 2011, 44, 774783.

26 L. Wang, M. Wang, P. D. Topham and Y. Huang, RSC Adv., 2012, 2, 2433-2438.

27 S. Sajeesh and C. P. Sharma, Int. J. Pharm., 2006, 325, 147-154.

28 S. W. Kuo and F. C. Chang, Macromolecules, 2001, 34, 52245228.

29 S. E. Paramonov, H.-W. Jun and J. D. Hartgerink, J. Am. Chem. Soc., 2006, 128, 7291-7298.

30 W. Li, B. Lu, A. Sheng, F. Yang and Z. Wang, J. Mol. Struct., 2010, 981, 194-203.

31 G. J. Thomas, Jr, Annu. Rev. Biophys. Biophys. Chem., 1999, 28, 1-27.

32 O. Iranzo, D. Ghosh and V. L. Pecoraro, Inorg. Chem., 2006, 45, 9959-9973.

33 W. Bae and R. K. Mehra, J. Inorg. Biochem., 1997, 68, 201-210.

34 A. Adach, J. Janyst and M. Cieślak-Golonka, Spectrosc. Lett., 1995, 28, 1259-1273.

35 S. Chakraborty, J. Yudenfreund Kravitz, P. W. Thulstrup, L. Hemmingsen, W. F. DeGrado and V. L. Pecoraro, Angew. Chem., Int. Ed., 2011, 50, 2049-2053.

36 S. Potocki, M. Rowinska-Zyrek, D. Valensin, K. Krzywoszynska, D. Witkowska, M. Luczkowski and H. Kozlowski, Inorg. Chem., 2011, 50, 6135-6145. 